\title{
Association of glucose levels and glucose variability with mood in type 1 diabetic patients
}

\author{
N. Hermanns • C. Scheff • B. Kulzer • P. Weyers • \\ P. Pauli • T. Kubiak • T. Haak
}

Received: 19 October 2006 / Accepted: 11 February 2007 / Published online: 17 March 2007

(C) Springer-Verlag 2007

\begin{abstract}
Aims/hypothesis The aim of this study was to investigate the association of glucose levels and variability of glucose, assessed by continuous glucose monitoring, with mood in type 1 diabetic patients.

Materials and methods Thirty-six type 1 diabetic patients (77.8\% male, age: $31.1 \pm 10.0$ years; disease duration: $14.7 \pm$ 7.1 years, BMI: $26.7 \pm 5.1 \mathrm{~kg} / \mathrm{m}^{2}, \mathrm{HbA}_{1 \mathrm{c}} 8.4 \pm 1.8 \%, 27.8 \%$ with continuous subcutaneous insulin infusion [CSII] therapy) used a continuous glucose monitoring system for $48.8 \mathrm{~h}$. During this time the patients rated their current mood states 14.6 times on average, using the University of Wales Institute of Science and Technology Mood Adjective Checklist and hand-held computers.

Results Sensor performance was satisfactory, with a mean absolute difference from reference laboratory glucose measurement of $13.7 \%$. Current glucose values were significantly associated with ratings of 'tension' $(z=2.40)$, 'hedonic tone' $(z=-2.63)$ and 'energetic arousal' $(z=-2.09)$. 'Anger' $(z=1.64)$ was not significantly associated with glucose values. The glucose AUC during the $60 \mathrm{~min}$ prior to the mood rating showed similar associations. The two param-
\end{abstract}

N. Hermanns $(\triangle) \cdot$ C. Scheff $\cdot$ B. Kulzer $\cdot$ T. Haak

Research Institute of the Diabetes Academy Mergentheim (FIDAM),

Postfach 1144, 97961 Bad Mergentheim, Germany

e-mail: hermanns@diabetes-zentrum.de

P. Weyers $\cdot$ P. Pauli

Department of Psychology, University of Wuerzburg,

Wuerzburg, Germany

T. Kubiak

Institute of Psychology, University of Greifswald,

Greifswald, Germany eters of glucose variability - coefficient of variation and absolute glucose change during the $60 \mathrm{~min}$ prior to the mood ratings - did not show any significant association with the mood ratings. The magnitude of association was significantly higher for glucose level than for glucose variability in the scales 'tension' and 'hedonic tone'. Conclusions/interpretation High glucose values had a negative impact on mood; positive mood ratings decreased, whereas negative mood ratings increased. The association between mood and glucose variability seemed to be less important than that between glucose level and mood.

Keywords Devices - Metabolic physiology in vivo . Psychological aspects

$\begin{array}{ll}\text { Abbreviations } & \\ \text { CGMS } & \text { continuous glucose monitoring system } \\ \text { CSII } & \text { continuous subcutaneous insulin infusion } \\ \text { hHC } & \text { Und-held computers } \\ \text { UWIST Mood } & \text { University of Wales Institute of Science } \\ \text { Adjective } & \text { and Technology Mood Adjective } \\ \text { Checklist } & \text { Checklist }\end{array}$

\section{Introduction}

Negative emotional symptoms such as symptoms of depression or anxiety are more common in diabetic patients than in the non-diabetic population [1-4]. In spite of patients' anecdotal reports about an association between blood glucose and emotional well-being, the impact of blood glucose on mood is not yet fully understood. Since the first systematic research on this topic [5], studies only analysed the association between a single spot blood 
glucose measurement and mood ratings. The novel glucose sensor technology provides new opportunities to study not only the impact of glucose levels on emotional factors in diabetic patients but also (due to the continuous measurement of glucose) the association between mood and glucodynamic parameters such as glucose variability. This study investigated the association of mood symptoms with current glucose level and glucose variability.

\section{Subjects and methods}

Type 1 diabetic patients at the Mergentheim diabetes centre were asked if they would participate in a study about the association between glucose values and mood. Patients who gave informed consent were included. The study was approved by the ethics committee.

Measurement of glycaemia The patients used the Medtronic MiniMed Continuous Glucose Monitoring System (CGMS; Medtronic MiniMed, Northridge, CA, USA). The CGMS allowed only the retrospective analysis of glucose values; thus, except for calibration measurements, the patients were blind to their current glucose level. The CGMS provided a glucose value every $5 \mathrm{~min}$ during the monitoring time. To assess the performance of the CGMS, capillary blood glucose was routinely measured six times per day by a standard laboratory measurement (Ebio Photometer; Eppendorf-Netheler-Hinz GmbH, Hamburg, Germany). Calibration measurements for the CGMS were also performed according to this laboratory method.

Mood assessment During the CGMS measurement period, patients also used hand-held computers (HHCs) (Psion 3a; Psion plc, London, UK) to record measurement time and complete the UWIST Mood Adjective Checklist (University of Wales Institute of Science and Technology Mood Adjective Checklist) [6] several times. During the valid monitoring time, the participants performed on average $15.7 \pm 8.4 \mathrm{mood}$ assessments using this questionnaire. The UWIST Mood Adjective Checklist consists of 28 mood-related adjectives. The subjects had to rate the applicability of each adjective to their present mood as 'definitely', 'slightly', 'slightly not' or 'definitely not'. Responses were scored from 4 for 'definitely' to 1 for 'definitely not'. Four scales, produced by addition of the single-item scores 'hedonic tone' (eight items, scale range 8-32, Cronbach's $\alpha=0.90$ ), 'energetic arousal' (eight items, scale range $8-32$, Cronbach's $\alpha=0.85$ ), 'tension' (seven items, scale range 7-28, Cronbach's $\alpha=0.83$ ), and 'anger' (five items, scale range 5-20, Cronbach's $\alpha=0.77$ ), demonstrated sufficient internal consistency. The German translation of the UWIST mood checklist was validated in a previous study [7]. After completion of the assessment procedures, data from the CGMS and the HHCs were downloaded to a computer and mood data were assigned to the CGMS data of the same time interval (5 min).

Statistical analysis As parameters representing glucose level, we used the current glucose value during the mood rating and the AUC 60 min prior to the mood rating.

As indicators of glucose variability, the variation coefficient of glucose values during the $60 \mathrm{~min}$ prior to the mood ratings and the absolute change of current glucose values from the glucose value $60 \mathrm{~min}$ prior to the mood ratings were used. Mood scores were normalised by use of the McCall transformation of the test scores to area-transformed $\mathrm{Z}$ values.

To assess the association between mood ratings, glucose level and glucose variability, multilevel regression analyses were performed in which data could be nested within each participant. Dependent variables were the normalised scores of the mood scales. The multilevel regression analyses were controlled for the number of mood ratings, insulin regimen (multiple injection therapy vs continuous subcutaneous insulin infusion [CSII] therapy) and time of day of mood rating $(1=06.00-12.00 \mathrm{~h} ; 2=12.00-18.00 \mathrm{~h} ; 3=18.00$ $00.00 \mathrm{~h}$ ). Different multilevel regression models were compared with each other using a likelihood ratio test to determine whether associations between mood ratings and glucose levels differed significantly from associations between mood ratings and glucose variability.

\section{Results}

Participants in this study were 36 type 1 diabetic patients (77.8\% male, age: $31.1 \pm 10.0$ years; disease duration: $14.7 \pm$ 7.1 years, BMI: $26.7 \pm 5.1 \mathrm{~kg} / \mathrm{m}^{2}, \mathrm{HbA}_{1 \mathrm{c}} 8.4 \pm 1.8 \%, 25.7 \%$ with CSII therapy, all other patients had multiple injection therapy with $5.7 \pm 1.7$ insulin injections per day).

Sensor performance The sensor performance and course of glucose during the observation period are shown in Table 1. The accuracy of the glucose sensor measurement compared with the reference glucose measurement is acceptable. But there was a slight negative difference in the hypoglycaemic range, whereas there was a slight positive difference between CGMS and the reference glucose measurement in the hyperglycaemic range. On average, patients had a valid observation time of continuous glucose monitoring of $48.8 \mathrm{~h}$. The patients spent most of their daily observation time $(18 \mathrm{~h})$ in a euglycaemic range; only 2.5 and $3.5 \mathrm{~h}$ were spent daily in a hypoglycaemic and a hyperglycaemic range, respectively. The mean glucose level was close to that of euglycaemia. In the hypo- and hyperglycaemic ranges, mean glucose values indicated rather moderate hypo- and hyperglycaemia. 
Table 1 Performance and results of CGMS and outcome of mood ratings

\begin{tabular}{|c|c|c|c|c|}
\hline & All & $\begin{array}{l}\text { Hypoglycaemic range } \\
(<3.9 \mathrm{mmol} / \mathrm{l})\end{array}$ & $\begin{array}{l}\text { Euglycaemic range } \\
(3.9-10 \mathrm{mmol} / \mathrm{l})\end{array}$ & $\begin{array}{l}\text { Hyperglycaemic range } \\
(>10 \mathrm{mmol} / \mathrm{l})\end{array}$ \\
\hline Number of reference glucose measurements & 500 & 63 & 360 & 77 \\
\hline $\begin{array}{l}\text { Mean difference from reference glucose } \\
\text { level }^{\mathrm{a}} \text { and } 95 \% \text { limits of agreement } \\
(\mathrm{mmol} / \mathrm{l})\end{array}$ & $\begin{array}{l}0.1 \pm 1.26 \\
(-2.45 \text { to } 2.59)\end{array}$ & $\begin{array}{l}-0.55 \pm 0.91 \\
(-2.37 \text { to }-1.27)\end{array}$ & $\begin{array}{l}0.03 \pm 1.1 \\
(-2.17 \text { to } 2.23)\end{array}$ & $\begin{array}{l}0.61 \pm 1.74 \\
(-2.87 \text { to } 4.09)\end{array}$ \\
\hline Mean absolute difference (\%) & $13.7 \pm 15.1$ & $21.7 \pm 27.3$ & $12.5 \pm 11.7$ & $11.1 \pm 10.3$ \\
\hline $\begin{array}{l}\text { Correlation with reference glucose } \\
\text { level }(r)\end{array}$ & 0.92 & 0.44 & 0.78 & 0.79 \\
\hline Valid monitor time $(\mathrm{h})$ & $48.8 \pm 16.1$ & $5.0 \pm 5.6$ & $37.0 \pm 14.9$ & $6.8 \pm 6.7$ \\
\hline Duration per day (h) & - & $2.5 \pm 2.5$ & $18.0 \pm 3.7$ & $3.5 \pm 3.6$ \\
\hline Mean sensor glucose readings (mmol/l) & $7.0 \pm 2.9$ & $3.1 \pm 0.6$ & $6.6 \pm 1.6$ & $12.7 \pm 2.4$ \\
\hline $\begin{array}{l}\text { Number of correlations between } \\
\text { glucose level and mood per patient }\end{array}$ & $14.6 \pm 8.2$ & $1.1 \pm 1.8$ & $11.8 \pm 7.7$ & $1.7 \pm 1.8$ \\
\hline $\begin{array}{l}\text { Number of pairs between mood } \\
\text { ratings and glucose reading }\end{array}$ & 525 & 40 & 425 & 60 \\
\hline Tension (median, range) & $11.4(7-28)$ & $10.1(7-24)$ & $11.4(7-28)$ & $14.0(7-24)$ \\
\hline Hedonic tone (median, range) & $27(8-32)$ & $29(11-32)$ & $27(8-32)$ & $24(9-32)$ \\
\hline Anger (median, range) & $6(5-20)$ & $5(5-20)$ & $6(5-19)$ & $7(5-19)$ \\
\hline Energetic arousal (median, range) & $27.4(8-32)$ & $28.6(8-32)$ & $27.4(8-32)$ & $26.9(9-32)$ \\
\hline
\end{tabular}

${ }^{\mathrm{a}}$ (Reference glucose measurement)-(sensor glucose measurement)

${ }^{\mathrm{b}}$ The $95 \%$ limits of agreement are reported in brackets (2 SD below and above, respectively, the mean difference).

Associations between glucose levels and mood Results of the multilevel regression analyses are shown in Table 2. There were significant negative associations between 'hedonic tone', on the one hand, and current glucose values and the AUC during the 60 min prior to the mood rating, on the other hand. 'Energetic arousal' was significant negatively associated with glucose values. The negative mood state 'tension' showed significant positive associations with

Table 2 Results ( $z$ scores) of multilevel regression analysis with patient as nested factor between mood ratings and glucose level and glucose variability, and comparison of magnitude of associations (log the current glucose values and the AUC, whereas the scale 'anger' was not significantly associated. From the magnitude of the association, it seems that the current glucose values have a slightly greater association with mood ratings than the AUC.

Associations between glucose variability and mood Multilevel regression analyses were also performed to assess the

likelihood ratio) between parameters of glucose level vs parameters of glucose variability

\begin{tabular}{|c|c|c|c|c|}
\hline & Tension & Hedonic tone & Anger & Energetic arousal \\
\hline \multicolumn{5}{|l|}{ Mood rating and glucose ${ }^{\mathrm{a}}$} \\
\hline \multicolumn{5}{|l|}{ Glucose level } \\
\hline Glucose value & $2.40^{*}$ & $-2.63 * *$ & 1.64 & $-2.09 *$ \\
\hline AUC & $1.97 *$ & $-2.08^{*}$ & $1.81^{* *}$ & $-1.76^{* *}$ \\
\hline \multicolumn{5}{|l|}{ Glucose variability } \\
\hline Absolute change & -0.50 & 0.82 & -0.72 & -0.07 \\
\hline Coefficient of variation & -0.55 & -0.40 & 0.36 & -0.08 \\
\hline \multicolumn{5}{|l|}{ Magnitude of association $^{\mathrm{b}}$} \\
\hline \multicolumn{5}{|c|}{ Log likelihood ratio for glucose value } \\
\hline vs coefficient of variation & $5.41 *$ & $6.68^{*}$ & 2.54 & $4.35^{*}$ \\
\hline vs absolute change & $5.46^{*}$ & $6.17 *$ & 2.16 & $4.35^{*}$ \\
\hline \multicolumn{5}{|l|}{ Log likelihood ratio for AUC } \\
\hline vs coefficient of variation & 3.56 & $4.13^{*}$ & 3.14 & 3.09 \\
\hline vs absolute change & 3.61 & 3.62 & 2.76 & 3.10 \\
\hline
\end{tabular}

$* p<0.05, * * p<0.10$

${ }^{a}$ Multilevel regression analysis is controlled for participant as nested factor, time of day the mood rating occurred $(1=06.00-12.00 \mathrm{~h} ; 2=12.00$ $18.00 \mathrm{~h} ; 3=18.00-00.00 \mathrm{~h}$ ), therapeutic regimen (multiple injection therapy vs CSII therapy), and number of mood ratings per patient.

${ }^{\mathrm{b}}$ Ratios were tested for significance using $\chi^{2}$ distribution. 
association between mood scales and the two parameters of glucose variability. There was no significant association.

Differences between multilevel regression analyses Differences of the associations between mood and glucose levels on the one hand and between mood and glucose variability on the other were tested for significance. The associations between mood and glucose levels (glucose values and AUC) were significantly higher than for mood and glucose variability (variation coefficient and absolute change) in the scales 'tension' and 'hedonic tone.' In the scales 'anger' and 'energetic arousal,' the associations of glucose level with mood were all stronger than the associations between glucose variability and mood, but the differences between the associations failed to reach significance, except for the scale 'energetic arousal.'

\section{Discussion}

The accuracy of sensor performance is slightly higher than previous findings regarding the accuracy of needle-type sensors [8]. In spite of a slight overestimation of low glucose values and a slight underestimation of high glucose values it can be assumed that the accuracy of the sensor performance is sufficient in this study.

The duration of euglycaemic glucose phases was remarkably longer than normative data of an American (US) sample of type 1 diabetic patients indicated, whereas hyperglycaemic glucose phases lasted a shorter time. Duration of hypoglycaemia was similar to the observations in the US sample [9].

Higher glucose values were associated primarily with negative mood states. With higher glucose values, feelings of anger and tension increased, whereas positive feelings such as feelings of energy or hedonic tone decreased. This finding strengthens the argument for pursuing near-normal glycaemic control in type 1 diabetic patients.

Since CGMS allows one not only to assess the association between mood ratings and current glucose level but also to study glucodynamic effects on mood, we were also able to compare the associations between glucose level parameters and glucose variability. The relevant data indicated no significant associations between mood ratings and glucose variability. Thus the association between glucose levels and mood states seemed to be more important than that between mood states and glucose variability.

When interpreting the results of this investigation, one should consider possible limitations of the study. The sample size was rather small and the sample consisted of only type 1 diabetic patients. In this study, observed glucose values in the hyperglycaemic range were rather moderate compared with US data [9]. Thus, it cannot be excluded that the observed relationship between hyperglycaemia and negative mood states would have been more pronounced if the degree of hyperglycaemia had been greater.

Although CGMS data were analysed only retrospectively, it cannot be excluded that occasional mood ratings may have been accompanied by glucose self-tests by the patients.

The novelty of this study is that the impacts on mood of both glucose level and glucose variability were assessed simultaneously for the first time. The study results seem to indicate a small but significant negative impact of hyperglycaemia on mood, but a less important effect of glucose variability on mood. Further investigations could pursue the clinically as well as physiologically interesting questions of whether these results can be confirmed in other patient groups and settings and at different degrees of glycaemic control.

Acknowledgements Consumable supplies for CGMS were kindly provided free of charge by Medtronic MiniMed Germany (Dusseldorf). Results were presented in part at the annual scientific meeting of the German Diabetes Association, 2005, in Berlin.

Duality of interest None of the authors had any conflicting interests in connection with this study.

\section{References}

1. Hermanns N, Kulzer B, Krichbaum M et al (2005) Affective and anxiety disorders in a German sample of diabetic patients: prevalence, comorbidity and risk factors. Diabet Med 22:293-300

2. Peyrot M, Rubin RR (1997) Levels and risks of depression and anxiety symptomatology among diabetic adults. Diabetes Care 20:585-590

3. Anderson RJ, Freedland KF, Clouse RE et al (2001) The prevalence of comorbid depression in adults with diabetes. Diabetes Care 24:1069-1078

4. Grigsby AB, Anderson RJ, Freedland KE et al (2002) Prevalence of anxiety in adults with diabetes: a systematic review. J Psychosom Res 53:1053-1060

5. Gonder-Frederick LA, Cox DJ, Bobbitt SA et al (1989) Mood changes associated with blood glucose fluctuations in insulindependent diabetes mellitus. Health Psychol 8:45-59

6. Matthews GM, Jones DM, Chamberlain AG (1990) Refining the measurement of mood: the UWIST Mood Adjective Checklist. Br J Psychol 81:17-42

7. Hermanns N, Kubiak T, Kulzer B et al (2003) Emotional changes during experimentally induced hypoglycaemia in type 1 diabetes. Biol Psychol 63:15-44

8. Wentholt IM, Vollebregt MA, Hart AA et al (2005) Comparison of a needle-type and a microdialysis continuous glucose monitor in type 1 diabetic patients. Diabetes Care 28:2871-2876

9. Bode BW, Schwartz S, Stubbs HA et al (2005) Glycemic characteristics in continuously monitored patients with type 1 and type 2 diabetes: normative values. Diabetes Care 28:2361-2366 